\title{
Placas de refratários aluminosos do sistema de válvula gaveta de panelas de aciaria: análise post mortem da degradação química
}

\section{(Refractory alumina plates used in the sliding gate system of steelmaking ladle: chemical degradation analysis of post mortem plates)}

\author{
B. B. de Sousa, S. R. Bragança \\ Universidade Federal do Rio Grande Sul, DEMAT, Av. Osvaldo Aranha, 99/711, Porto Alegre, RS 90035-190 \\ brunabertidesousa@gmail.com
}

\begin{abstract}
Resumo
Em uma aciaria, os recipientes que comportam o aço líquido, tais como o forno e a panela de aciaria, são revestidos com materiais refratários especiais para alta temperatura e elevada resistência ao desgaste. O custo desses materiais é alto e, portanto, almeja-se aumentar sua vida útil sem afetar seu desempenho. Este trabalho teve o objetivo de investigar as transformações que ocorrem no material refratário aluminoso de placas de válvula gaveta de panela de aciaria. Para tanto, a região das placas post mortem que entraram em contato com o material líquido a alta temperatura foi caracterizada por meio de análise visual e análises de composição e estrutura através das técnicas de fluorescência de raios $\mathrm{X}$, difração de raios X e análise de microestrutura por microscopia eletrônica de varredura com espectroscopia por dispersão em energia. Como resultado, têm-se contribuições sobre o processo de corrosão química proporcionada pelo contato de escórias residuais com o canal das placas da válvula gaveta. Constatou-se a presença de materiais com alto teor de $\mathrm{Ca}$ e compostos por fases como mervinita e guelenita, características de escória, aderidos às placas. Ao mesmo tempo, foi possível estabelecer que a espessura de interação entre o material aderido e a superfície da placa variou entre 0,4 e 1,2 mm. Assim, quando associada à erosão pelo fluxo de aço, a corrosão química decorrente do contato com a escória tem o potencial de intensificar o desgaste da placa refratária.

Palavras-chave: refratários, placas, corrosão, alumina, siderurgia.
\end{abstract}

\begin{abstract}
In steelmaking, the refractory materials have to be special as they have to resist high temperature and wear situations in service. These special refractory materials are expensive, for this reason the steel industry aims to increase the service life of these materials keeping its performance. The goal of this work was to investigate the transformations that take place in the ladle slide gate plates material while in service. To accomplish this goal the region of post mortem plates that get in contact with the molten material was characterized by visual analysis and chemical composition analysis such as X-ray fluorescence techniques, X-ray diffraction and scanning electron microscopy with energy dispersive spectroscopy. The results are some contributions on the chemical corrosion process generated by the chemical interaction between residual slag and the plates. Materials with high calcium content and composed of merwinite and gehlenite, slag characteristic phases, were found to be adhered to the plates. Moreover, it was possible to establish that the thickness of the interaction zone between the adhered material and the surface of the plate varied between 0.4 and $1.2 \mathrm{~mm}$. Thus, when combined with erosion due to steel outflow, chemical corrosion resulting from contact with the slag has the potential to intensify wear on refractory plate channel.
\end{abstract}

Keywords: plates, refractories, corrosion, aluminum oxide, steelmaking.

\section{INTRODUÇÃO}

A competitividade do atual mercado de produção de aço tem crescido nas últimas décadas com o desenvolvimento das economias chinesa e indiana. Isso incentiva as empresas a buscarem formas de baixar custos mantendo a qualidade do seu produto, garantindo a segurança de seus colaboradores e evitar o uso de recursos naturais desnecessários. Uma forma de atingir essa meta é aumentando a vida útil de peças estratégicas como, por exemplo, o conjunto de peças refratárias que abrem e fecham o fluxo de aço da panela do refino secundário, denominado conjunto de placas (Fig. 1) [1]. A falha ou desgaste excessivo desse conjunto requer a parada da produção, aumentando, inclusive, o risco de vazamento de aço líquido sobre a área industrial. Sendo assim, é de extrema importância que essas peças sejam projetadas de forma a resistir às condições operacionais, mantendo-se íntegras ao longo do processo de refino. Por conseguinte, as peças são feitas de materiais de alto desempenho, como $\mathrm{Al}_{2} \mathrm{O}_{3}-\mathrm{C}, \mathrm{Al}_{2} \mathrm{O}_{3}-\mathrm{ZrO}_{2}-\mathrm{C}$, entre outros [2]. $\mathrm{O}$ custo unitário das peças é relativamente elevado.

As condições de serviço na indústria siderúrgica são severas e, portanto, apesar desses materiais serem projetados para esta aplicação, diversos níveis de degradação podem ocorrer em decorrência do uso. $\mathrm{O}$ uso de placas refratários contendo carbono é comum e traz, entre outros benefícios, a diminuição da penetração de escória líquida nos poros do material devido ao menor molhamento de sua superfície 


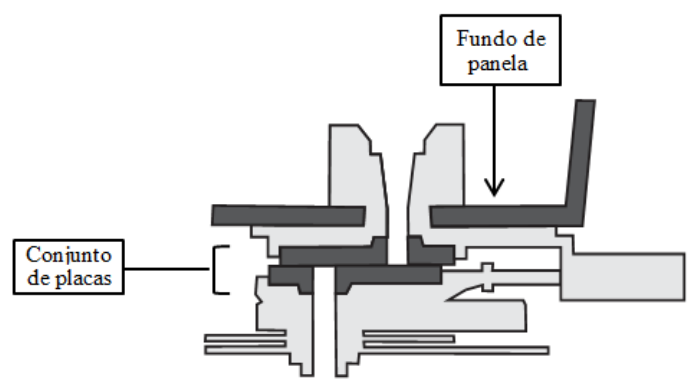

Figura 1: Sistema de válvula gaveta da panela da aciaria na posição fechado.

[Figure 1: Ladle slide gate system in the closed position.]

proporcionado pela presença de carbono. No entanto, durante o serviço, forma-se uma camada descarbonizada na superfície do refratário, a qual é menos resistente à infiltração da escória, levando à corrosão, dissolução e erosão de grãos do óxido [3]. O conhecimento sobre a dinâmica de corrosão do material refratário é relevante, uma vez que pode proporcionar melhorias na operação e na seleção de materiais que visem o aumento da vida útil das placas. É importante mencionar que as condições operacionais escolhidas por cada usina também podem ter impacto direto na vida útil das peças. Por exemplo, podese escolher trabalhar com um maior nível residual de aço na panela após o lingotamento, ou maximizar a quantidade produzida por corrida. Nesta segunda opção, eventualmente, ocorre a passagem de escória, a qual passa a ter contato com as placas refratárias. Existe ainda a possibilidade de se instalar o controle de fechamento automatizado de válvula gaveta, auxiliado por sistemas de detecção da passagem de escória. Na tomada de decisões, juntamente ao custo de instalação de tais equipamentos, é importante considerar o efeito da corrosão química por escória na vida de placas.

Para melhorar o processo é preciso uma maior compreensão do mecanismo e das causas do desgaste das placas. Para tanto, pode-se fazer caracterização de placas post-mortem que tiveram desgaste intenso, sendo este o objetivo do presente artigo. Este estudo é uma sequência do trabalho [1], no qual foi realizada a caracterização de diferentes placas refratárias e investigadas as propriedades de placas post mortem, para casos onde não houve, visualmente, a interação de escória com as placas. No presente trabalho foram investigados casos em que se observou a presença de escória aderida às placas $\mathrm{Al}_{2} \mathrm{O}_{3}-\mathrm{ZrO}_{2}-\mathrm{C}$. Portanto, foi priorizado o estudo da corrosão química das placas. Desse modo, foram feitas análises de composição química, das fases minerais e a caracterização microestrutural com análise química pontual via microscopia eletrônica de varredura e espectroscopia por dispersão em energia (MEV/EDS), de amostras das regiões de placas post mortem de válvula gaveta que entraram em contato com a escória.

\section{EXPERIMENTAL}

As placas de válvula gaveta estudadas foram constituídas do sistema $\mathrm{Al}_{2} \mathrm{O}_{3}-\mathrm{ZrO}_{2}-\mathrm{C}$, sendo impregnadas com piche e coqueificadas. Como mostrado no esquema da Fig. 2, o

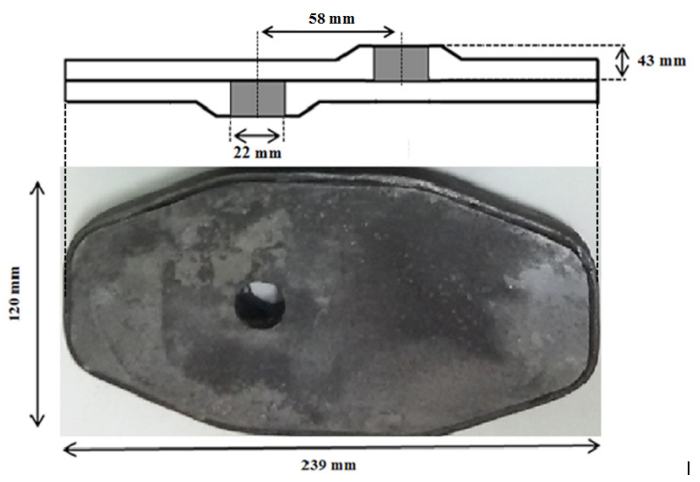

Figura 2: Esquema mostrando dimensões aproximadas da placa. [Figure 2: Scheme showing the approximate plate dimensions.]

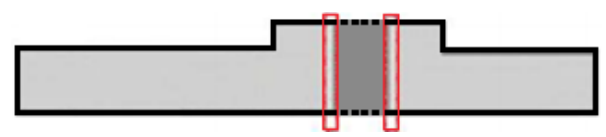

Figura 3: Região do canal da placa de onde foram retiradas as amostras.

[Figure 3: Gate region of the plate where the samples were taken.]

Tabela I - Fases do banco de dados cristalográfico identificadas e a simbologia usada no trabalho. [Table I - Phases of the crystallographic database identified and the symbols used on the work.]

\begin{tabular}{cccc}
\hline Símbolo & Nome do composto & Fórmula química & Código PDF 2 ICDD, 2003 \\
\hline$\circ$ & Coríndon & $\mathrm{Al}_{2} \mathrm{O}_{3}$ & $01-071-1127$ \\
$\Delta$ & Badeleíta & $\mathrm{ZrO}_{2}$ & $01-074-1200$ \\
$\Delta$ & Grafite & $\mathrm{C}$ & $00-001-0640$ \\
$\diamond$ & Magnetita & $\mathrm{Fe}_{3} \mathrm{O}_{4}$ & $01-089-0691$ \\
$\square$ & Guelenita & $\mathrm{Al}_{2} \mathrm{Ca}_{2} \mathrm{SiO}_{7}$ & $00-001-0982$ \\
$\bullet$ & Mervinita & $\mathrm{Ca}_{3} \mathrm{MgSi}_{2} \mathrm{O}_{8}$ & $00-026-1064$ \\
$\square$ & Calcita & $\mathrm{CaCO}_{3}$ & $00-047-1743$ \\
$\bullet$ & Silicato dicálcico & $\mathrm{Ca}_{2} \mathrm{SiO}_{4}$ & $01-087-1257$ \\
$\mathbb{Q}$ & Periclásio & $\mathrm{MgO}$ & $01-075-1525$ \\
\hline PDF 2 - Powder Diffraction File (banco de dados). ICDD - International Centre for Diffraction Data.
\end{tabular}


curso de abertura da válvula foi de $58 \mathrm{~mm}$, o comprimento da placa foi de $239 \mathrm{~mm}$, a largura de $120 \mathrm{~mm}$, o diâmetro do furo de cada placa de $22 \mathrm{~mm}$ e a profundidade de cada furo de $43 \mathrm{~mm}$. Neste estudo foram analisadas placas postmortem de válvula gaveta de panela de aciaria depois de usadas cerca de quatro vezes, apresentando material aderido com aspecto tipicamente de escória. Retiraram-se amostras de material da área que ficou em contato com o aço líquido durante o lingotamento, como indicado na Fig. 3, as quais foram caracterizadas.

Realizaram-se análises de microscopia eletrônica de varredura (MEV) e espectroscopia por dispersão em energia (EDS, Hitachi TM3000/Swift ED 3000), análise química por método semiquantitativo de concentração aproximada de elementos químicos em amostras que não possuem padrão primário de comparação por fluorescência de raios X (FRX Shimadzu, XRF-1800, com fonte de radiação de Rh, potência de $4 \mathrm{~kW}$, operado em $40 \mathrm{kV}$ e $80 \mathrm{~mA}$ ) e difração de raios X (DRX Philips X'Pert MPD, Philips Analytical Netherlands) empregando radiação $\mathrm{CuK} \alpha$, goniômetro $\theta-\theta$, operando em um intervalo angular de varredura em $2 \theta$ de $5^{\circ}$ a $75^{\circ}$ com passo de $0,05 \%$. A Tabela I apresenta todas as fases cristalinas identificadas neste estudo. Para facilitar a interpretação dos resultados, todas as análises realizadas neste estudo seguem a simbologia apresentada.

\section{RESULTADOS E DISCUSSÃO}

Análise visual: a região próxima ao orifício do canal das placas post mortem foi analisada e perceberam-se materiais de aparência diversa aderidos, como mostrado na Fig. 4. As amostras foram retiradas e identificadas por letras e descritas na Tabela II.

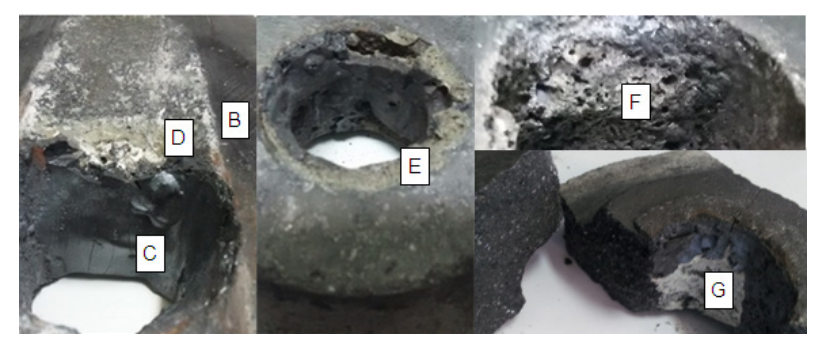

Figura 4: Material da placa post mortem próximo do canal (B) e materiais aderidos à placa post mortem: material preto aderido ao canal da placa post mortem (C), material esverdeado aderido à extremidade do canal da placa que faz interface com a outra placa do conjunto de placas do sistema de válvula gaveta (D), material esverdeado aderido à extremidade do canal da placa que faz interface com o bocal (E), material poroso aderido ao canal $(\mathrm{F})$ e material esbranquiçado aderido ao canal $(\mathrm{G})$.

[Figure 4: Post mortem plate material near the plate channel (B) and materials adhered to the post mortem plate: black material adhered to the post mortem plate channel $(C)$, green material adhered to the end of the channel that faces the other plate of the pair of the slide gate system (D), green material adhered to the end of the channel that faces nozzle of the slide gate system, (E), porous material adhered to the plate channel $(F)$, and white material adhered to the plate channel $(G)$.]
Tabela II - Identificação de amostras. [Table II - Samples identification.]

\begin{tabular}{|c|c|}
\hline $\begin{array}{l}\text { Nome da } \\
\text { amostra }\end{array}$ & Descrição da amostra \\
\hline A & Material da placa nova \\
\hline $\mathrm{B}$ & $\begin{array}{l}\text { Material de aparência similar à da placa nova } \\
\text { em região próxima do canal da placa post } \\
\text { mortem }\end{array}$ \\
\hline $\mathrm{C}$ & $\begin{array}{l}\text { Material preto aderido ao canal da placa post } \\
\text { mortem }\end{array}$ \\
\hline $\mathrm{D}$ & $\begin{array}{c}\text { Material esverdeado aderido à extremidade do } \\
\text { canal da placa post mortem em contato com a } \\
\text { outra placa }\end{array}$ \\
\hline $\mathrm{E}$ & $\begin{array}{c}\text { Material esverdeado aderido a extremidade do } \\
\text { canal da placa post mortem em contato com } \\
\text { a válvula, estando presente na mesma placa o } \\
\text { material D }\end{array}$ \\
\hline $\mathrm{F}$ & $\begin{array}{c}\text { Material poroso aderido ao canal da placa post } \\
\text { mortem }\end{array}$ \\
\hline G & $\begin{array}{l}\text { Material esbranquiçado quebradiço aderido ao } \\
\text { canal da placa post mortem }\end{array}$ \\
\hline $\mathrm{H}$ & Amostra da escória de forno panela \\
\hline
\end{tabular}

Caracterização da composição química (FRX): a composição da região degradada das placas foi obtida por análise química por FRX e pode ser verificada na Tabela III. A amostra retirada da região da placa post mortem (amostra B), próxima ao canal, e da placa nova (amostra A) demonstram composição com teores similares dos principais constituintes, sendo $73 \%$ a $77 \%$ de $\mathrm{Al}_{2} \mathrm{O}_{3}$ e $10 \%$ a $13 \%$ de $\mathrm{SiO}_{2}$. No entanto, a concentração de $\mathrm{ZrO}_{2}$ foi superior na placa post mortem. Isso ocorreu, provavelmente, pois o $\mathrm{ZrO}_{2}$ não se encontra distribuído homogeneamente na placa, mas sim em agregados dispersos na microestrutura. Outra diferença foi a maior concentração de $\mathrm{SiO}_{2}, \mathrm{CaO}$ e $\mathrm{Fe}_{2} \mathrm{O}_{3}$ na região analisada da placa post mortem, se comparada à placa nova. Isso provavelmente se deve à ocorrência de difusão de espécies presentes na escória e no aço líquido para o material da placa. A amostra $\mathrm{C}$ foi majoritariamente constituída de fases contendo ferro, provavelmente, referente ao aço que interagiu com o ar e os resquícios de escória aderidos à placa. Os demais materiais aderidos ao canal da placa, amostras $\mathrm{D}$, E, F e G, tiveram alto teor de $\mathrm{CaO}$, entre $37 \%$ e $52 \%$, bem como de outros elementos como o $\mathrm{SiO}_{2}$, com teor entre $16 \%$ e $20 \%$, o $\mathrm{Al}_{2} \mathrm{O}_{3}$, com teor entre $7 \%$ e $20 \%$, e $\mathrm{MgO}$, com teor entre $5 \%$ e $13 \%$, além de outros elementos em menor proporção. Isso indicou que os materiais aderidos foram resultado do contato da escória, amostra $\mathrm{H}$, com o canal da placa, uma vez que a escória apresentou alto percentual de $\mathrm{CaO}$ em sua composição, 55,41\%. A amostra $\mathrm{G}$, aderida no canal teve composição muito similar à do material poroso, amostra F. Ambos possuíram composição próxima à da escória, exceto pelo maior valor de alumina, provavelmente, oriundo da placa. 
B. B. de Souza et al. / Cerâmica 64 (2018) 41-48

Tabela III - Composição química via FRX das amostras: (A) placa nova; (B) material da placa post mortem; (C) material preto aderido ao canal da placa post mortem; (D) material esverdeado aderido à extremidade do canal da placa que faz interface com a outra placa do sistema de válvula gaveta; (E) material esverdeado aderido à extremidade do canal da placa que faz interface com o bocal do sistema de válvula gaveta, estando presente na mesma placa o material D; (F) material poroso aderido ao canal; (G) material esbranquiçado aderido ao canal e (H) escória.

[Table III - Chemical composition obtained by XRF of the samples: (A) new plate, (B) post mortem plate material near the channel, (C) black material adhered to the post mortem plate channel, (D) green material adhered to the end of the channel that faces the other plate of the pair of the slide gate system, (E) green material adhered to the end of the channel that faces nozzle of the slide gate system, $(G)$ porous material adhered to the plate channel $(F)$, white material adhered to the plate channel, and (H) ladle slag.]

\begin{tabular}{ccccccccc}
\hline Óxido $(\%$ em massa $)$ & $\mathrm{A}$ & $\mathrm{B}$ & $\mathrm{C}$ & $\mathrm{D}$ & $\mathrm{E}$ & $\mathrm{F}$ & $\mathrm{G}$ & $\mathrm{H}$ \\
\hline $\mathrm{Al}_{2} \mathrm{O}_{3}$ & 76,5 & 73,8 & 10,3 & 7,0 & 14,9 & 18,8 & 20,0 & 4,2 \\
$\mathrm{ZrO}_{2}$ & 5,8 & 0,2 & $<0,1$ & $<0,1$ & 0,3 & 0,1 & 0,7 & $<0,1$ \\
$\mathrm{SiO}_{2}$ & 12,8 & 18,5 & 11,4 & 20,6 & 18,7 & 16,1 & 16,7 & 22,0 \\
$\mathrm{Fe}_{2} \mathrm{O}_{3}$ & 0,2 & 0,7 & 53,2 & 0,6 & 11,7 & 5,0 & 6,3 & 3,2 \\
$\mathrm{CaO}$ & 0,3 & 1,3 & 18,2 & 51,4 & 37,5 & 45,0 & 44,0 & 55,4 \\
$\mathrm{Na}_{2} \mathrm{O}$ & $<0,1$ & 0,4 & $<0,1$ & $<0,1$ & $<0,1$ & $<0,1$ & 0,2 & $<0,1$ \\
$\mathrm{~K}_{2} \mathrm{O}$ & 0,0 & 0,6 & 0,0 & 0,1 & 0,1 & $<0,1$ & 0,2 & $<0,1$ \\
$\mathrm{HfO}$ & 0,1 & 0,2 & $<0,1$ & $<0,1$ & $<0,1$ & $<0,1$ & 0,1 & $<0,1$ \\
$\mathrm{MnO}_{2}$ & 0,0 & $<0,1$ & 0,6 & 1,6 & 2,9 & 0,5 & 0,8 & 1,8 \\
$\mathrm{Cr}_{2} \mathrm{O}_{3}$ & 0,9 & $<0,1$ & $<0,1$ & $<0,1$ & $<0,1$ & $<0,1$ & $<0,1$ & 0,2 \\
$\mathrm{SO}_{3}$ & 0,1 & $<0,1$ & $<0,1$ & 0,6 & 0,3 & 1,1 & 0,8 & 0,7 \\
$\mathrm{P}_{2} \mathrm{O}_{5}$ & $<0,1$ & $<0,1$ & $<0,1$ & $<0,1$ & $<0,1$ & 0,2 & 0,0 & 0,0 \\
$\mathrm{MgO}^{\mathrm{TiO}}$ & $<0,1$ & $<0,1$ & 4,2 & 12,1 & 8,5 & 9,2 & 5,7 & 3,5 \\
$\mathrm{BaO}_{2}$ & $<0,1$ & $<0,1$ & 0,2 & 0,6 & 0,4 & 0,5 & 0,5 & 0,7 \\
& $<0,1$ & $<0,1$ & $<0,1$ & $<0,1$ & 0,2 & $<0,1$ & $<0,1$ & $<0,1$ \\
\hline
\end{tabular}

Caracterização mineralógica (DRX): a Fig. 5 mostra os difratogramas das amostras. Na amostra da placa nova (amostra A) e na de placa post mortem (amostra B) observase a presença das fases cristalinas coríndon $\left(\mathrm{Al}_{2} \mathrm{O}_{3}\right)$, grafite (C) e badeleíta $\left(\mathrm{ZrO}_{2}\right)$ sugerindo que não houve formação significativa de novas fases no material da placa onde não houve material aderido, mesmo na região próxima ao canal. A amostra de material escuro (amostra $\mathrm{C}$ ) revelou que o mesmo é magnetita $\left(\mathrm{Fe}_{3} \mathrm{O}_{4}\right)$, o que está de acordo com o FRX e, portanto, confirma que é resultado de resquícios de aço que oxidaram presentes no canal. Os materiais aderidos $\mathrm{D}, \mathrm{E}$ e $\mathrm{F}$ apresentaram fases características da escória, a guelenita $\left(\mathrm{Al}_{2} \mathrm{Ca}_{2} \mathrm{SiO}_{7}\right)$, mervinita $\left[\mathrm{Ca}_{3} \mathrm{Mg}\left(\mathrm{SiO}_{4}\right)_{2}\right]$ e a cal recarbonatada (calcita, $\mathrm{CaCO}_{3}$ ) [4]. A calcita $\left(\mathrm{CaCO}_{3}\right.$ ) foi provavelmente resultado da hidratação da cal $(\mathrm{CaO})$ gerada pelo contato com a umidade do ar que forma $\mathrm{Ca}\left(\mathrm{OH}_{2}\right)$ (Eq. A) e que por sua vez se transforma em calcita $\left(\mathrm{CaCO}_{3}\right)$ ao entrar em contato com o dióxido de carbono $\left(\mathrm{CO}_{2}\right)$ (Eq. B) [5].

$$
\begin{aligned}
& \mathrm{CaO}_{(\mathrm{s})}+\mathrm{H}_{2} \mathrm{O} \rightarrow \mathrm{Ca}(\mathrm{OH})_{2(\mathrm{~s})} \\
& \mathrm{Ca}(\mathrm{OH})_{2(\mathrm{~s})}+\mathrm{CO}_{2(\mathrm{~g})} \rightarrow \mathrm{CaCO}_{3(\mathrm{~s})}+\mathrm{H}_{2} \mathrm{O}
\end{aligned}
$$

As amostras $\mathrm{E}$ e $\mathrm{G}$ ainda contêm resquícios de coríndon $\left(\mathrm{Al}_{2} \mathrm{O}_{3}\right)$, provavelmente proveniente da interface do material com a placa. Esse resultado está de acordo com o obtido na FRX uma vez que os elementos que constituem essas fases são majoritários nos resultados de composição química dessas amostras. O material $\mathrm{G}$, além das fases contidas nas amostras D, E e F, apresentou também outras fases encontradas na escória, como periclásio $(\mathrm{MgO})$ e silicato dicálcico $\left(\mathrm{Ca}_{2} \mathrm{SiO}_{4}\right)$. Isso sugeriu que o material aderido $\mathrm{G}$ sofreu modificações menos intensas que o D, E e F. Ele pode, por exemplo, ser resultante da última corrida, enquanto os outros ficaram aderidos à placa por várias corridas, sendo modificados por interações químicas em razão de processos de difusão e ação da temperatura.

Estudos sobre as reações de $\mathrm{CaO}$ na matriz de sílica $\left(\mathrm{SiO}_{2}\right)$ e alumina $\left(\mathrm{Al}_{2} \mathrm{O}_{3}\right)$ mostram que durante o escoamento do fluxo pela válvula gaveta, a sílica presente reage com a cal $(\mathrm{CaO})$, formando wollastonita $\left(\mathrm{CaO} \cdot \mathrm{SiO}_{2}\right)$ (Eq. C). Esse silicato pode reagir novamente com a cal, formando $\gamma$-silicato dicálcico $\left(\mathrm{Ca}_{2} \mathrm{SiO}_{4}\right)$ (Eq. D).

$$
\begin{aligned}
& \mathrm{CaO}+\mathrm{SiO}_{2}=\mathrm{CaO} \cdot \mathrm{SiO}_{2} \\
& \mathrm{CaO}+\mathrm{CaO} \cdot \mathrm{SiO}_{2}=\mathrm{Ca}_{2} \mathrm{SiO}_{4}
\end{aligned}
$$

Estas reações propiciam a formação de uma escória com grande concentração de silicato dicálcico $\left(\mathrm{Ca}_{2} \mathrm{SiO}_{4}\right)$ como 


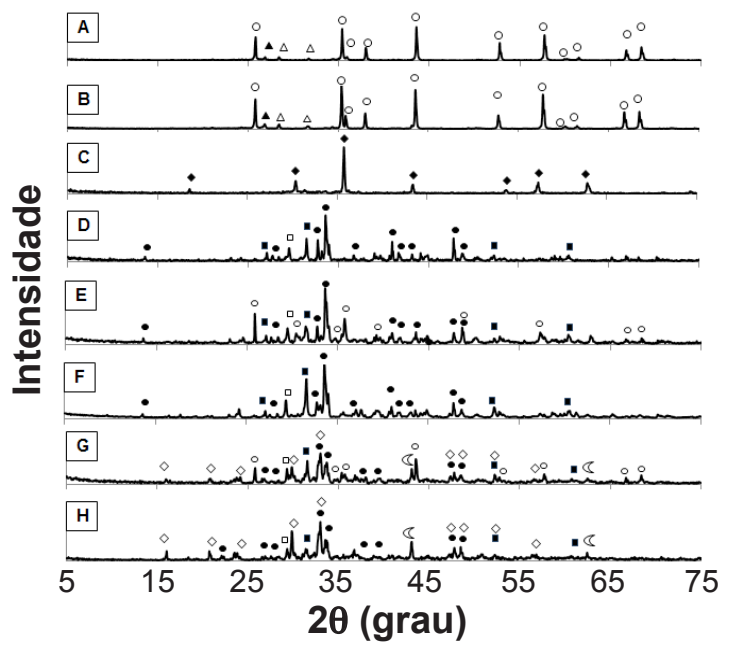
- Corídon $\left(\mathrm{Al}_{2} \mathrm{O}_{3}\right)$
$\square$ Calcita $\left(\mathrm{CaCO}_{3}\right)$
- Guelenita $\left(\mathrm{Al}_{2} \mathrm{Ca}_{2} \mathrm{SiO}_{7}\right)$
- Mervinita $\left(\mathrm{Ca}_{3} \mathrm{Mg}\left(\mathrm{SiO}_{4}\right)_{2}\right)$
- Magnetita $\left(\mathrm{Fe}_{2} \mathrm{O}_{4}\right)$
$\Delta$ Grafite (C)
$\triangle$ Badeleita $\left(\mathrm{ZrO}_{2}\right)$
$\diamond$ Silicato dicálcico $\left(\mathrm{Ca}_{2} \mathrm{SiO}_{4}\right)$
\& Periclásio (MgO)

Figura 5: Difratogramas de raios $\mathrm{X}$ das amostras: $\mathrm{A}$ e $\mathrm{B}$ indicam a presença das fases coríndon $\left(\mathrm{Al}_{2} \mathrm{O}_{3}\right)$, grafite $(\mathrm{C})$ e badeleíta $\left(\mathrm{ZrO}_{2}\right) ; \mathrm{C}$ indica a presença de magnetita $\left(\mathrm{Fe}_{3} \mathrm{O}_{4}\right)$; e D, E, F e G indicam a presença de fases características de escória como guelenita $\left(\mathrm{Al}_{2} \mathrm{Ca}_{2} \mathrm{SiO}_{7}\right)$, mervinita $\left[\mathrm{Ca}_{3} \mathrm{Mg}\left(\mathrm{SiO}_{4}\right)_{2}\right]$ e calcita $\left(\mathrm{CaCO}_{3}\right)$, além de alumina $\left(\mathrm{Al}_{2} \mathrm{O}_{3}\right)$ em $\mathrm{E}$ e $\mathrm{G}$, provavelmente resquício da superfície de contato da placa com o material aderido.

[Figure 5: X-ray diffraction patterns of samples: A and $\mathrm{B}$ indicate presence of corundum $\left(\mathrm{Al}_{2} \mathrm{O}_{3}\right)$, graphite (C) and baddeleyite $\left(\mathrm{ZrO}_{2}\right) ; \mathrm{C}$ indicates presence of magnetite $\left(\mathrm{Fe}_{3} \mathrm{O}_{4}\right)$; and $\mathrm{D}, \mathrm{E}, \mathrm{F}$ and $\mathrm{G}$ indicate presence of typical slag phases such as gehlenite ( $\left.\mathrm{Al}_{2} \mathrm{Ca}_{2} \mathrm{SiO}_{7}\right)$, merwinite $\left[\mathrm{Ca}_{3} \mathrm{Mg}\left(\mathrm{SiO}_{4}\right)_{2}\right]$, and calcite $\left(\mathrm{CaCO}_{3}\right)$, besides corundum $\left(\mathrm{Al}_{2} \mathrm{O}_{3}\right)$ in $\mathrm{E}$ and $\mathrm{G}$, probably remnant of the contact surface between the plate and the adhered material.]

foi identificado na análise da amostra de escória $\mathrm{H}$ [6]. A formação de guelenita $\left(\mathrm{Al}_{2} \mathrm{Ca}_{2} \mathrm{SiO}_{7}\right)$ pode ocorrer devido à reação da alumina presente na matriz com silicato de cálcio, mas também ela pode se formar diretamente pela reação da alumina do refratário com os componentes da escória (Eq. E) $[2,7]$.

$$
2 \mathrm{CaO}+\mathrm{Al}_{2} \mathrm{O}_{3}+\mathrm{SiO}_{2} \rightarrow \mathrm{Al}_{2} \mathrm{Ca}_{2} \mathrm{SiO}_{7}
$$

Além de ser uma fase de temperatura de fusão relativamente baixa, $1590{ }^{\circ} \mathrm{C}$, a guelenita conhecidamente pode reagir com outras fases do sistema ternário $\mathrm{Al}_{2} \mathrm{O}_{3}-\mathrm{SiO}_{2}-$ $\mathrm{CaO}$ (Fig. 6) como a anortita e, dessa forma, gerar fases de temperatura de fusão de até $1265^{\circ} \mathrm{C}$. Essas temperaturas são inferiores ou relativamente próximas à temperatura de lingotamento, $1560{ }^{\circ} \mathrm{C}$, propiciando a fusão ou dissolução desses compostos quando em contato com o fluxo de aço líquido. Isso propicia o desgaste das regiões do refratário

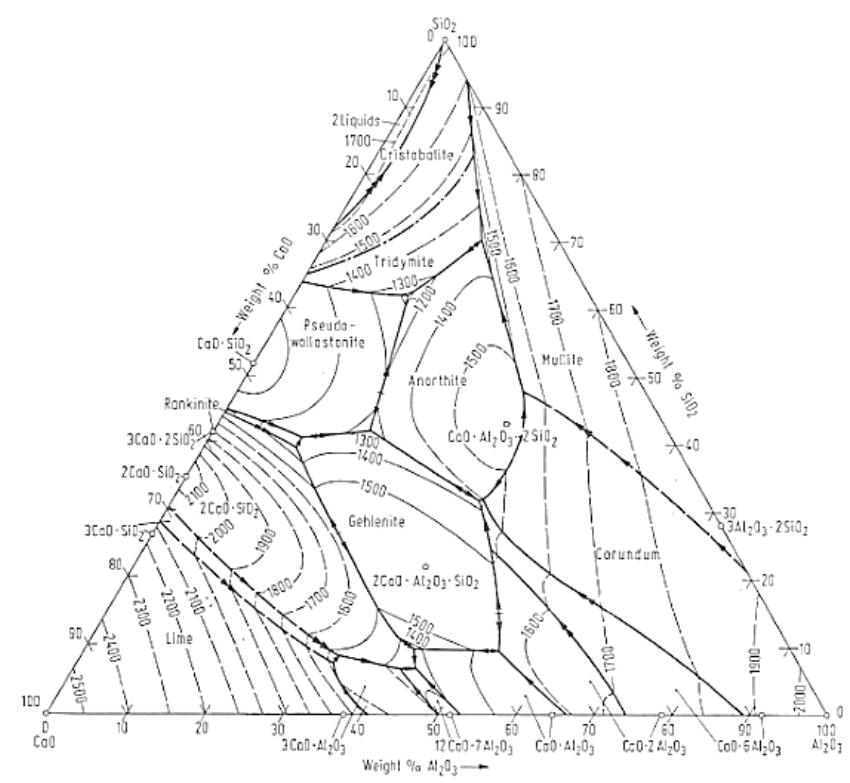

Figura 6: Diagrama de fases ternário $\mathrm{Al}_{2} \mathrm{O}_{3}-\mathrm{SiO}_{2}-\mathrm{CaO}$ segundo Muan e Osborn [8].

[Figure 6: Ternary phase diagram $\mathrm{Al}_{2} \mathrm{O}_{3}-\mathrm{SiO}_{2}-\mathrm{CaO}$ by Muan and Osborn [8].]

em que há a formação da guelenita $\left(\mathrm{Al}_{2} \mathrm{Ca}_{2} \mathrm{SiO}_{7}\right)$ e, consequentemente, o aumento de porosidade [2].

Caracterização microestrutural (MEV/EDS) microestrutura da superficie do canal: as imagens obtidas por MEV na Fig. 7 mostram regiões do canal de uma das placas post mortem com material aderido proveniente
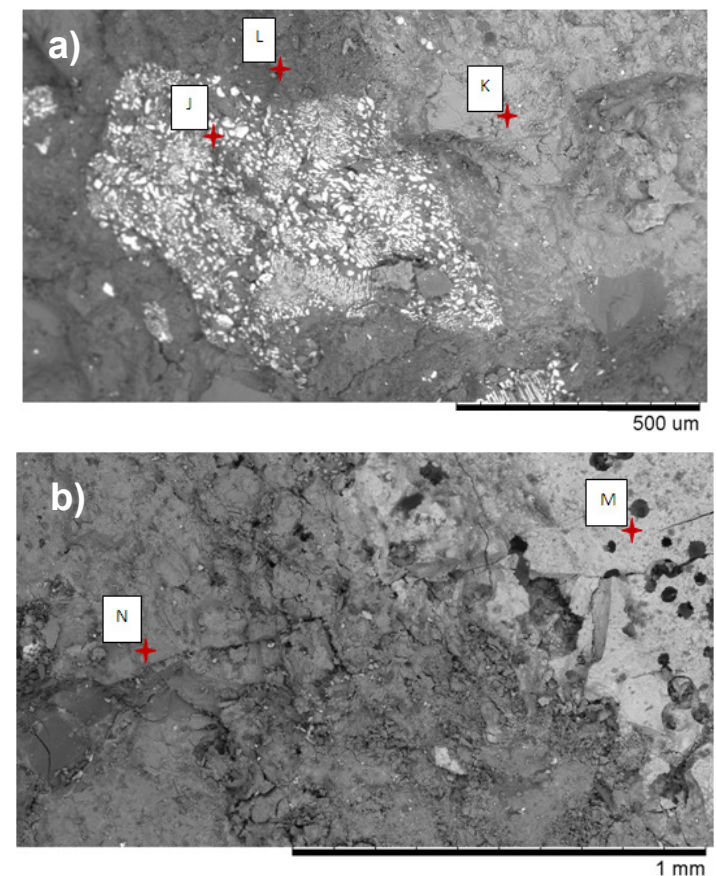

Figura 7: Micrografias obtidas por microscopia eletrônica de varredura de materias aderidos ao canal da placa de aciaria indicando os pontos $\mathrm{J}, \mathrm{K}, \mathrm{L}, \mathrm{M}$ e $\mathrm{N}$ onde foram feitas análises de composição semiquantitativa via EDS.

[Figure 7: SEM micrographs of the materials adhered to the plate channel and the spots identified as $J, K, L, M$ and $N$ where semiquantitative chemical compositions were obtained by EDS.] 
Tabela IV - Composição semiquantitativa (\% em massa) por EDS dos pontos J, K, L, M e N do canal da placa (Fig. 7). [Table IV - Chemical composition (wt\%) obtained by EDS of the spots on the plate channel $J, K, L, M$ and $N$ indicated in Fig. 7.]

\begin{tabular}{cccccc}
\hline Elemento & $\mathrm{J}$ & $\mathrm{K}$ & $\mathrm{L}$ & $\mathrm{M}$ & $\mathrm{N}$ \\
\hline Carbono & 15,8 & 4,1 & 32,1 & 11,6 & 5,2 \\
Oxigênio & 36,4 & 36,0 & 44,1 & 32,3 & 50,3 \\
Sódio & 0,4 & 0,0 & 0,2 & 0,0 & 0,0 \\
Magnésio & 0,2 & 0,6 & 0,0 & 0,0 & 0,9 \\
Alumínio & 7,1 & 13,9 & 19,1 & 5,7 & 14,3 \\
Silício & 3,8 & 6,0 & 2,9 & 3,6 & 8,4 \\
Enxofre & 0,0 & 0,0 & 0,1 & 0,0 & 0,0 \\
Cálcio & 1,0 & 36,6 & 0,3 & 7,7 & 20,1 \\
Manganês & 0,6 & 0,8 & 0,3 & 0,0 & 0,0 \\
Ferro & 0,0 & 0,7 & 0,1 & 39,1 & 0,4 \\
Zircônio & 32,8 & 1,3 & 0,8 & 0,0 & 0,0 \\
Ouro & 1,9 & 0,0 & 0,0 & 0,0 & 0,0 \\
Estanho & 0,0 & 0,0 & 0,0 & 0,0 & 0,4 \\
\hline
\end{tabular}

da escória. As composições qualitativas obtidas via EDS dessas regiões, J, K, L, M e N, são apresentadas na Tabela IV. A partir dos resultados da Tabela IV, é possível concluir que a região $\mathrm{J}$ é um agregado de zircônia, e a região $\mathrm{K}$ e $\mathrm{N}$ são constituídas de alumina e, principalmente, cal, sendo, portanto, regiões de material aderido ou de reação entre material aderido e placa. A região L, na Fig. 7a, composta principalmente por Alé, provavelmente, o material da própria placa; e a região $\mathrm{M}$ na Fig. $7 \mathrm{~b}$ é composta principalmente de $\mathrm{Fe}$, sendo, portanto, aço fundido que ficou aderido durante o lingotamento. Outras placas post mortem também foram analisadas por MEV e EDS e os resultados foram similares aos apresentados.

Caracterização microestrutural (MEV/EDS) - interface de reação: a Fig. 8 mostra um esquema que ilustra o local da interface entre a placa post mortem com material aderido onde foi feita a imagem por MEV (Fig. 9). As regiões identificadas com números 1 a 8 indicam regiões analisadas via EDS, cujos resultados são apresentados na Tabela V, sendo a distância entre a região 1 e 8 de cerca de $2,2 \mathrm{~mm}$. Esta análise mostrou claramente a variação composicional ao longo da região. A Fig. 10 destaca o aumento de Ca e a diminuição de $\mathrm{Al}$ da placa em direção ao material aderido. A partir da variação da composição foi possível supor a faixa de espessuras dentro da qual está a zona de reação da interface. Assim, verificou-se que houve uma provável zona de interação entre a superfície da placa e o material aderido de espessura dentro da faixa de 0,4 a $1,2 \mathrm{~mm}$.

O diâmetro do canal de uma placa nova é de $23 \mathrm{~mm}$, no entanto, o diâmetro de uma placa post mortem pode alcançar em média um valor $57 \%$ maior [9]. Ao se considerar o valor da espessura de reação, supondo-se esta uma zona de degradação estrutural da peça, mesmo que seja complexo se

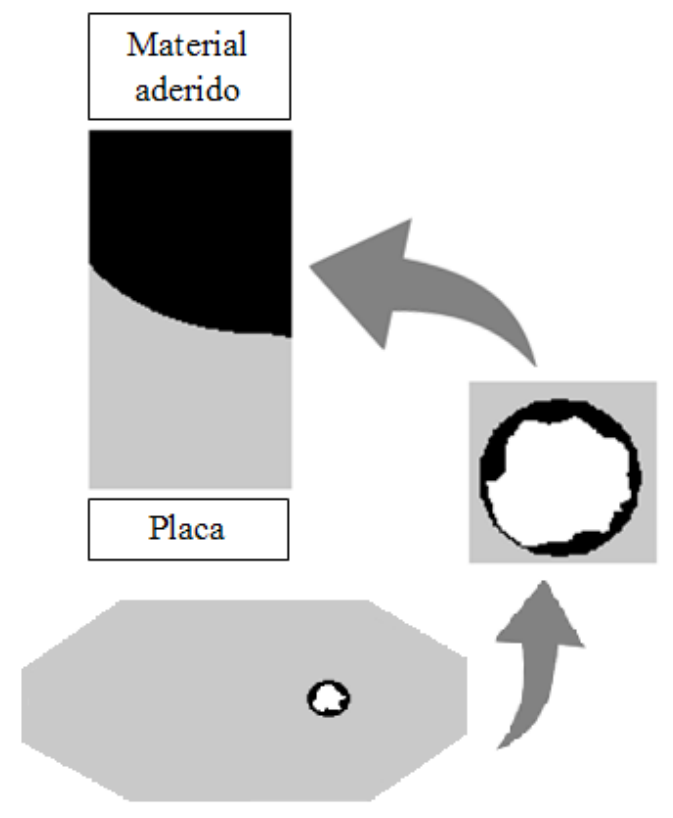

Figura 8: Esquema mostrando a região analisada na imagem obtida por MEV (Fig. 9).

[Figure 8: Scheme showing the region analyzed in the image obtained by SEM, Fig. 9.]

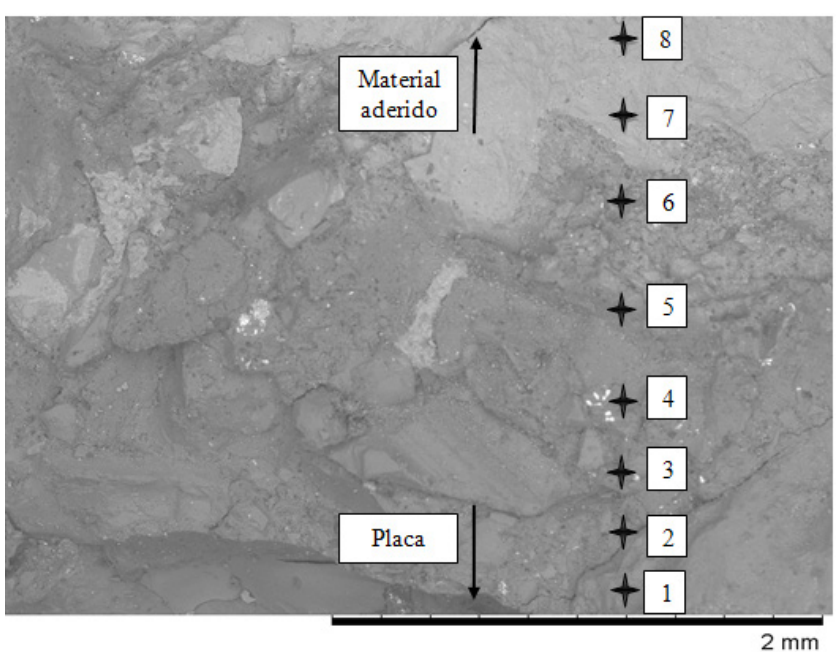

Figura 9: Micrografia obtida por microscopia eletrônica de varredura da interface entre o material aderido à superfície do furo e o material refratário. Os pontos numerados indicam as regiões da interface onde foram feitas análises de composição por EDS (Tabela V) com o objetivo de verificar a variação de composição na interface.

[Figure 9: SEM micrograph of the interface between the adhered material and the plate surface. The identified spots are the regions where chemical composition was obtained by EDS (Table V). This analysis aimed to verify the variation of chemical composition along the interface.]

precisar um valor numérico, nota-se que a contribuição da corrosão estando entre 0,4 e 1,2 $\mathrm{mm}$ é bastante significativa em relação ao aumento de diâmetro do canal de placa. Portanto, uma placa usada apresenta um desgaste cuja intensidade é o resultado da sinergia entre a degradação 
Tabela V - Composição química semiquantitativa (\% em massa) por EDS de oito regiões na direção transversal à interface entre material aderido e placa, sendo a região 1 a mais próxima da superfície da placa e a região 8 a mais próxima ao material aderido à placa (Figs. 9 e 10).

[Table V-Chemical composition (wt\%) obtained by EDS of eight spots on the transverse direction of the interface between the plate surface and the adhered material, being position 1 on the plate side and position 8 on the adhered material side (Figs. 9 and 10).]

\begin{tabular}{ccccccccc}
\hline Elemento & 1 & 2 & 3 & 4 & 5 & 6 & 7 & 8 \\
\hline $\mathrm{C}$ & 29,4 & 0,0 & 0,0 & 0,0 & 28,8 & 33,0 & 9,6 & 7,0 \\
$\mathrm{O}$ & 38,3 & 42,6 & 44,4 & 43,8 & 38,4 & 32,3 & 37,8 & 38,5 \\
$\mathrm{~F}$ & 0,0 & 0,0 & 0,0 & 0,0 & 0,0 & 4,9 & 0,0 & 0,0 \\
$\mathrm{Na}$ & 0,4 & 0,8 & 0,5 & 0,3 & 0,1 & 0,0 & 0,0 & 0,0 \\
$\mathrm{Mg}$ & 0,0 & 0,0 & 0,8 & 1,0 & 1,3 & 3,4 & 3,8 & 4,3 \\
$\mathrm{Al}$ & 20,6 & 36,5 & 32,5 & 31,6 & 18,4 & 3,9 & 3,2 & 2,3 \\
$\mathrm{Si}$ & 10,1 & 18,5 & 16,6 & 19,3 & 7,4 & 6,7 & 11,4 & 11,4 \\
$\mathrm{~S}$ & 0,0 & 0,0 & 0,0 & 0,0 & 0,0 & 0,2 & 0,0 & 0,0 \\
$\mathrm{~K}$ & 0,0 & 0,4 & 0,2 & 0,3 & 0,0 & 0,0 & 0,0 & 0,0 \\
$\mathrm{Ca}$ & 0,4 & 1,2 & 3,4 & 3,2 & 4,9 & 11,6 & 33,1 & 35,5 \\
$\mathrm{Ti}$ & 0,0 & 0,0 & 0,0 & 0,0 & 0,2 & 0,7 & 0,0 & 0,0 \\
$\mathrm{Cr}$ & 0,0 & 0,0 & 0,0 & 0,0 & 0,0 & 0,3 & 0,0 & 0,0 \\
$\mathrm{Mn}$ & 0,3 & 0,0 & 0,5 & 0,0 & 0,3 & 1,4 & 1,1 & 0,0 \\
$\mathrm{Fe}$ & 0,0 & 0,0 & 0,4 & 0,0 & 0,2 & 1,3 & 0,0 & 0,9 \\
$\mathrm{Pt}$ & 0,5 & 0,0 & 0,0 & 0,6 & 0,0 & 0,0 & 0,0 & 0,0 \\
$\mathrm{Zr}$ & 0,0 & 0,0 & 0,7 & 0,0 & 0,0 & 0,3 & 0,0 & 0,0 \\
\hline
\end{tabular}

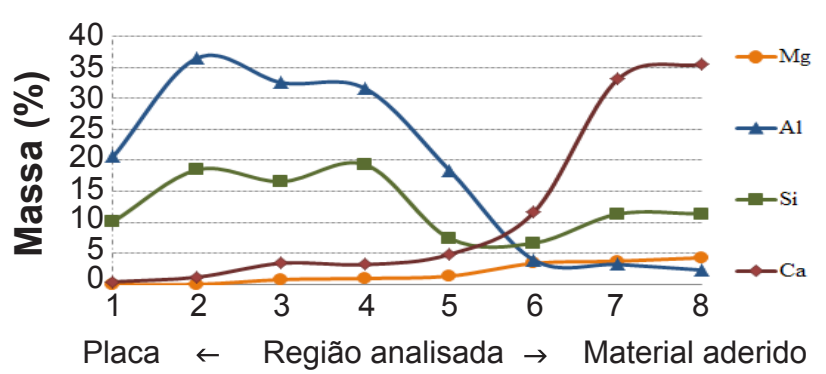

Figura 10: Gráfico mostrando a variação dos elementos $\mathrm{Mg}, \mathrm{Al}, \mathrm{Si}$ e Ca no decorrer da interface entre a placa post mortem e o material aderido. As regiões 1, 2, 3, 4, 5, 6, 7 e 8 são indicadas na Fig. 9 , sendo a região 1 na placa e a região 8 no material aderido. A composição em cada região é apresentada na Tabela $\mathrm{V}$ e mostra que ocorre variação acentuada nos percentuais de $\mathrm{Ca}$ e $\mathrm{Al}$ entre a região 4 e 7.

[Figure 10: Graph showing the variation of the elements $\mathrm{Mg}, \mathrm{Al}, \mathrm{Si}$ and $\mathrm{Ca}$ in the course of the interface between the post mortem plate and the material. The regions 1, 2, 3, 4, 5, 6, 7 and 8 are shown in Fig. 9. Region 1 is the plate and region 8 is the adhered material. The composition in each region is shown in Table $V$. The graph shows that there is a marked variation in $\mathrm{Ca}$ and Al percentage between region 4 and 7.$]$

química, a qual reduz a resistência mecânica da mesma, mais a intensa erosão causada pelo fluxo de aço. Este, muitas vezes, pode dificultar a percepção da ação de corrosão, já que renova a superfície, retirando os compostos (fases) de corrosão. Consequentemente, o mecanismo de degradação de placas apresenta-se em uma sequência semelhante à de outros materiais refratários, quanto à corrosão, mas também com a peculiaridade do forte desgaste erosivo pelo aço. Essa corrosão apresenta semelhança ao mecanismo proposto de corrosão de refratários óxido-C como proposto em [3]: perda de carbono, molhagem, corrosão química, abrasão/ erosão. Assim, a erosão atua de modo independente e/ou sinérgico à corrosão.

\section{CONCLUSÕES}

As análises indicaram a presença de fases constituídas de elementos como $\mathrm{Al}$ e $\mathrm{Ca}$, possivelmente, como produto da reação química das placas com a escória que fica aderido à placa após o uso. Como é conhecido, o $\mathrm{CaO}$ pode formar eutéticos com a alumina e contribuir para a degradação das placas aluminosas a altas temperaturas, levando à remoção das camadas reagidas da placa pelo fluxo de aço passante. As diferenças de aparência, composição e estrutura dos materiais aderidos à placa são, provavelmente, resultado de exposição a condições de tempo, temperatura e área superficial diferentes, gerando assim condições cinéticas e termodinâmicas diferentes, que, por sua vez, podem propiciar variações por difusão e mudança de fase nos materiais. A variação de tais condições se deve provavelmente às mudanças de parâmetros de processo e operação peculiares ao refino secundário que ocorrem de uma corrida para outra, como os tempos e as temperaturas 
de operação, a ocorrência de entupimento que demande procedimento para forçar a abertura da válvula gaveta, o aço produzido e, consequentemente, a composição da escória, entre outras variáveis. Foi identificada a faixa de espessura em que está a zona de interação química entre a da placa e o material proveniente da escória aderida. No entanto, conhecendo o aumento médio de diâmetro de canal de placa ao fim de sua vida útil, entende-se que a corrosão química devida à presença de escória não atua sozinha na degradação do canal, mas de forma a facilitar a erosão decorrente da passagem do aço.

\section{AGRADECIMENTO}

À Coordenação de Aperfeiçoamento de Pessoal de Nível Superior (CAPES) pela bolsa de estudos de Mestrado.

\section{REFERÊNCIAS}

[1] B.B. de Sousa, S.R. Bragança, Cerâmica 63, 366 (2016) 216.
[2] Z.D. Nascimento, "Efeito do cálcio no desgaste das placas refratárias de válvula gaveta de distribuidor no processo de lingotamento contínuo", Diss. Mestr., Un. Fed. Ouro Preto (2007).

[3] W.E. Lee, S. Zhang, Int. Mater. Rev.44, 3 (1999) 77.

[4] J. Vlcek, R. Švrcinova, J. Burda, M. Topinkova, M. Klarova, H. Ovacaxikova, D.D. Jancar, M. Velicka, Metalurgija 55, 3 (2016) 399.

[5] W. Gu, D.W. Bousfield, C.P. Tripp, J. Mater. Chem. 16 (2006) 3312.

[6] J.A. Varela, Anais do Semin. COREF-COACO, ABM, S. Paulo (1991) 311

[7] W.S. Resende, C. Zirpoli, G.L. da Silva, Anais do $44^{\circ}$ Congr. Bras. Cerâmica, S. Paulo (2000) 495.1.

[8] Comittee for Fundamental Metallurgy, Slag Atlas, Verlag Stahleisen M.B.H, Düsseldorf (1981).

[9] B.B. de Sousa, "Avaliaçao da degradação de placas refratárias do mecanismo de válvula gaveta de panelas de aciaria", Trab. Concl. Curso, SABI UFRGS, Porto Alegre (2014).

(Rec. 08/07/2016, Rev. 09/08/2016, 10/11/2016, Ac. 10/11/2016) 